\title{
Genome duplication improves rice root resistance to salt stress
}

\author{
Yi Tư ${ }^{1 \dagger}$, Aiming Jiang ${ }^{1,4+}$, Lu Gan ${ }^{1,4}$, Mokter Hossain², Jinming Zhang ${ }^{1}$, Bo Peng ${ }^{1}$, Yuguo Xiong ${ }^{1}$, Zhaojian Song ${ }^{1}$, \\ Detian $\mathrm{Cai}^{1}$, Weifeng $\mathrm{Xu}^{2,3^{*}}$, Jianhua Zhang ${ }^{2}$ and Yuchi He $\mathrm{H}^{1,2^{*}}$
}

\begin{abstract}
Background: Salinity is a stressful environmental factor that limits the productivity of crop plants, and roots form the major interface between plants and various abiotic stresses. Rice is a salt-sensitive crop and its polyploid shows advantages in terms of stress resistance. The objective of this study was to investigate the effects of genome duplication on rice root resistance to salt stress.

Results: Both diploid rice (HN2026-2x and Nipponbare-2x) and their corresponding tetraploid rice (HN2026-4x and Nipponbare-4x) were cultured in half-strength Murashige and Skoog medium with $150 \mathrm{mM} \mathrm{NaCl}$ for 3 and 5 days. Accumulations of proline, soluble sugar, malondialdehyde (MDA), $\mathrm{Na}^{+}$content, $\mathrm{H}^{+}$(proton) flux at root tips, and the microstructure and ultrastructure in rice roots were examined. We found that tetraploid rice showed less root growth inhibition, accumulated higher proline content and lower MDA content, and exhibited a higher frequency of normal epidermal cells than diploid rice. In addition, a protective gap appeared between the cortex and pericycle cells in tetraploid rice. Next, ultrastructural analysis showed that genome duplication improved membrane, organelle, and nuclei stability. Furthermore, $\mathrm{Na}^{+}$in tetraploid rice roots significantly decreased while root tip $\mathrm{H}^{+}$efflux in tetraploid rice significantly increased.
\end{abstract}

Conclusions: Our results suggest that genome duplication improves root resistance to salt stress, and that enhanced proton transport to the root surface may play a role in reducing $\mathrm{Na}^{+}$entrance into the roots.

Keywords: Genome duplication; Proton transport; Root; Salt stress; Tetraploid rice

\section{Background}

Salt $\left(\mathrm{Na}^{+}\right)$stress constitutes an important environmental pressure, and elevated $\mathrm{Na}^{+}$levels in agricultural land adversely affects the quantity and quality of crop plants (Buchanan et al. 2005; Knäblein et al. 2006; Atkinson and Urwin 2012; Horie et al. 2012). Plants must cope with two major stresses under high salinity: osmotic stress (beginning at the early phase under salt stress), which is caused primarily by water deficits in plant tissues, and ionic stress (beginning at the latter phase under salt stress), which can be caused by the accumulation of $\mathrm{Na}^{+}$ and $\mathrm{Cl}^{-}$and by disturbance of the $\mathrm{K}^{+} / \mathrm{Na}^{+}$ratio in plant

\footnotetext{
* Correspondence: wfxu@issas.ac.cn; hyc@hubu.edu.cn

${ }^{\dagger}$ Equal contributors

${ }^{2}$ School of Life Sciences and State Key Laboratory of Agrobiotechnology, The

Chinese University of Hong Kong, Hong Kong, China

${ }^{1}$ Hubei Collaborative Innovation Center for Green Transformation of

Bio-Resources, Hubei University, Wuhan 430062, P.R. China

Full list of author information is available at the end of the article
}

cells (Yeo and Flowers 1986; Glenn and Brown 1999; Blumwald 2000; Munns and Tester 2008; Horie et al. 2012). During evolution, plants have developed several mechanisms to cope with salt stress at the biochemical and molecular level (Zhu 2002; Shinozaki et al. 2005; Kronzucker et al. 2006; Horie et al. 2009; Hauser et al. 2010). Among various mechanisms, control of ion movement across tonoplasts (and the plasma membrane) to maintain a low $\mathrm{Na}^{+}$concentration in the cytoplasm is a key cellular factor for survival under salt stress (Baisakh et al. 2012; Brini and Masmoudi 2012), and plants are known to maintain low cytoplasmic $\mathrm{Na}^{+}$via intracellular (Fukuda et al. 2004; Anil et al. 2005) and extracellular compartmentalization (Anil et al. 2005). Plants respond to salt stress by restricting the uptake of $\mathrm{Na}^{+}$, and adjustment of the cytoplasmic compartment is achieved by producing compatible osmolytes such as proline, mannitol, sorbitol, and glycine betaine ((Greenway and Munns 1980; Kavi Kishor et al. 2005; Yamada et al. 2005; 
Chyzhykova and Palladina 2006; Jayasekaran et al. 2006); $\mathrm{Xu}$ and Shi 2007; (Munns and Tester 2008; Amirjani 2011; Chutipaijit et al. 2011)). Ion accumulation in the cytosol (mainly $\left.\mathrm{K}^{+}\right)$and in the vacuole $\left(\mathrm{Na}^{+}\right.$, especially in salt-tolerant cultivars/species) is also important for osmotic adjustment of plant cells ((Gorham et al. 1987; Gorham et al. 1990); Glenn and Brown 1999; (Knäblein et al. 2006)). Osmotic adjustment by solute accumulation inside the cell is essential to reduce the cellular Yosm against an osmotic gradient between root cells and the outside saline solution, which eventually restores water uptake into roots during salinity stress (Greenway and Munns 1980).

Roots are important to plants for a wide variety of processes and serve as the major interface between the plant and various biotic and abiotic factors in the soil environment (Smet et al. 2012). Plants have evolved various strategies and mechanisms to resist salinity stress, in which both anatomical and physiological adaptations play key roles (Lazof and Cheeseman 1986; Kronzucker et al. 2006). Solutes and water move radially through the roots via a combination of apoplastic, symplastic, and transcellular pathways. The mechanisms by which $\mathrm{Na}^{+}$enters the shoots of plants remain unclear (Kronzucker and Britto 2011), but apoplastic transpirational bypass flow of water and solutes is known to play an important role in rice (Yeo et al. 1987; Ochiai and Matoh 2002). The apoplastic barriers in roots may also play a major role (Yeo et al. 1987; Anil et al. 2005; Gong et al. 2006). The majority of $\mathrm{Na}^{+}$that enters the shoots of rice plants occurs through "apoplastic bypass," whereby $\mathrm{Na}^{+}$ions move through the apoplast via solvent drag (Ranathunge et al. 2005), bypassing Casparian bands (Ochiai and Matoh 2002; Gong et al. 2006). In rice, the highly suberized endodermal barrier presents the major resistance to radial water flow (Miyamoto et al. 2001; Ranathunge et al. 2003). Casparian bands of the endodermis and exodermis play crucial roles in blocking apoplastic movement of ions and water into the stele of roots through the cortex, and these apoplastic barriers differ considerably in structure and function along the developing root (Chen et al. 2011; Krishnamurthy et al. 2011; Zhou et al. 2011). Characterization of the hydraulic conductivity of roots of both herbaceous and woody species indicated that unfavorable environmental conditions reduce hydraulic conductivity ((Kramer and Boyer 1995; Steudle and Heydt 1997; Steudle and Peterson 1998; Barrowclough et al. 2000; Miyamoto et al. 2001; Lee et al. 2005); Zimmermann et al. 2000). Furthermore, the chemical composition of suberin in the apoplastic barrier affects the hydraulic conductivity of roots (Schreiber et al. 2005).

Polyploidy, which is believed to play an important role in plant evolution and breeding, can significantly improve the function of resistance genes and enrich the range of genetic variation in these genes, thus increasing the adaptability of plants to dynamic environments (Adams and Wendel 2005; Chen and Tian 2007; Soltis et al. 2009). The discovery and application of polyploidy meiosis stability (PMeS) material for disrupting a low seed set rate may be used for polyploid rice breeding in the future. Rice plants are very important as food and experimental models (Krishnan et al. 2009), and polyploid rice may result in evolutionary dominance in terms of stress resistance (Cai et al. 2004; Cai et al. 2007; He et al. 2010; He et al. 2011). At this time, little information is available regarding the effects of abiotic stress in polyploid rice (Dong and Adams 2011). As cereal crops, polyploid wheat has been examined under salt stress. In a study on the variation in salt tolerance within a Georgian wheat germplasm collection, the endemic hexaploid winter wheat Triticum macha and the endemic tetraploid wheat Triticum timopheevii were among the most tolerant to salt stress (Badridze et al. 2009). In tetraploid wheat genotypes, $\mathrm{Na}^{+}$exclusion correlated well with salinity tolerance in the durum subspecies, and $\mathrm{K}^{+} / \mathrm{Na}^{+}$discrimination correlated to a lesser degree (Munns and James 2003). Other studies have shown that salt stress inhibited germination in all wheat genotypes, but the effect was more pronounced in Potohar (hexaploid, salt-sensitive) than other genotypes (Javed, F). Studies on cotton also showed that the subfunctionalization of genes duplicated by polyploidy occurred in response to abiotic stress conditions. Partitioning of duplicate gene expression in response to environmental stress may lead to duplicate gene retention during subsequent evolution (Liu and Adam 2007). In other plants, some studies have reported that citrus tetraploid genotypes are more tolerant of moderate saline stress than the diploid genotypes, and that citrus tetraploid rootstocks are more tolerant to salt stress than the corresponding diploid rootstock genotypes (Saleh et al. 2008; Mouhaya et al. 2010). In hexaploid Acanthophyllum species, the negative effects of salinity on some growth parameters, including protein content and antioxidant enzymes, decreased in tetraploid species (Meratanl et al. 2008). Rice is a salt-sensitive crop considered more sensitive to salt stress during the early seedling than reproductive stage (Flowers and Yeo 1981; Lutts et al. 1995; Hasanuzzaman et al. 2009). Few studies have explored the effect of genome duplication on rice development under salt stress. An earlier study reported that the application of PMeS alleviated the low seed set rate, leading researchers to investigate adaptability under adverse conditions (Cai et al. 2004; Cai et al. 2007; He et al. 2010; He et al. 2011). Some results suggested that salt stress has a large negative impact on seed germination and seedling growth in rice, but that genome duplication has positive roles in modulating salt stress adjustability in 
different rice cultivars (Jiang et al. 2013). Polyploidy is believed to facilitate increased plant adaptability to environmental extremes, and thus characterizing the developmental and morphological changes in roots of polyploid rice that protect against the excessive influx of $\mathrm{Na}^{+}$is important. This may also be promising for screening or generating salt-tolerant polyploid rice varieties. The present study examined the impact of genome duplication on rice roots during saline treatment to increase our understanding on the adaptability of polyploid rice to salt stress and on improving the adaptation of rice under salt stress.

\section{Results}

The effect of genome duplication on rice root growth under salt stress

The length, fresh weight, dry weight, and number of roots of polyploid rice cultivars were investigated to characterize the effects of genome duplication under salt stress. Our results demonstrated that salt stress significantly restricted rice root growth, irrespective of being diploid or tetraploid rice, and genome duplication improved root resistance in tetraploid rice by contributing to faster and better root growth in the presence of $150 \mathrm{mM} \mathrm{NaCl}$ (Figure 1). Root length was restricted in all species. Salt stress significantly decreased the length of the longest root, irrespective of being diploid or tetraploid rice. Moreover, compared with roots under normal conditions, the restriction degree of root length in the diploid was much stronger than that in the tetraploid. The fresh weight of total roots in tetraploid rice showed a more significant increase than in diploid rice under salt conditions. However, the fresh weight of total roots decreased in all rice tested after salt treatment, and no significant difference in the dry weight of total roots was observed, excluding HN2026-4x. In addition, the results suggested that the total number of roots existed no evident difference in both HN2026-4x and Nipponbare- $4 \mathrm{x}$ under salt stress, but significant differences were found in the two diploid rice materials with salt treatment (Figure 1).

\section{Proline accumulation in the roots of diploid and} tetraploid rice under salt stress

Free proline in roots of diploid and tetraploid rice subjected to $150 \mathrm{mM} \mathrm{NaCl}$ for 5 days was measured (Figure 2). The amount of free proline in tetraploid rice cultivars under salt stress varied greatly and increased compared to diploid cultivars. The amounts of free proline in HN2026-2x and Nipponbare-2x were

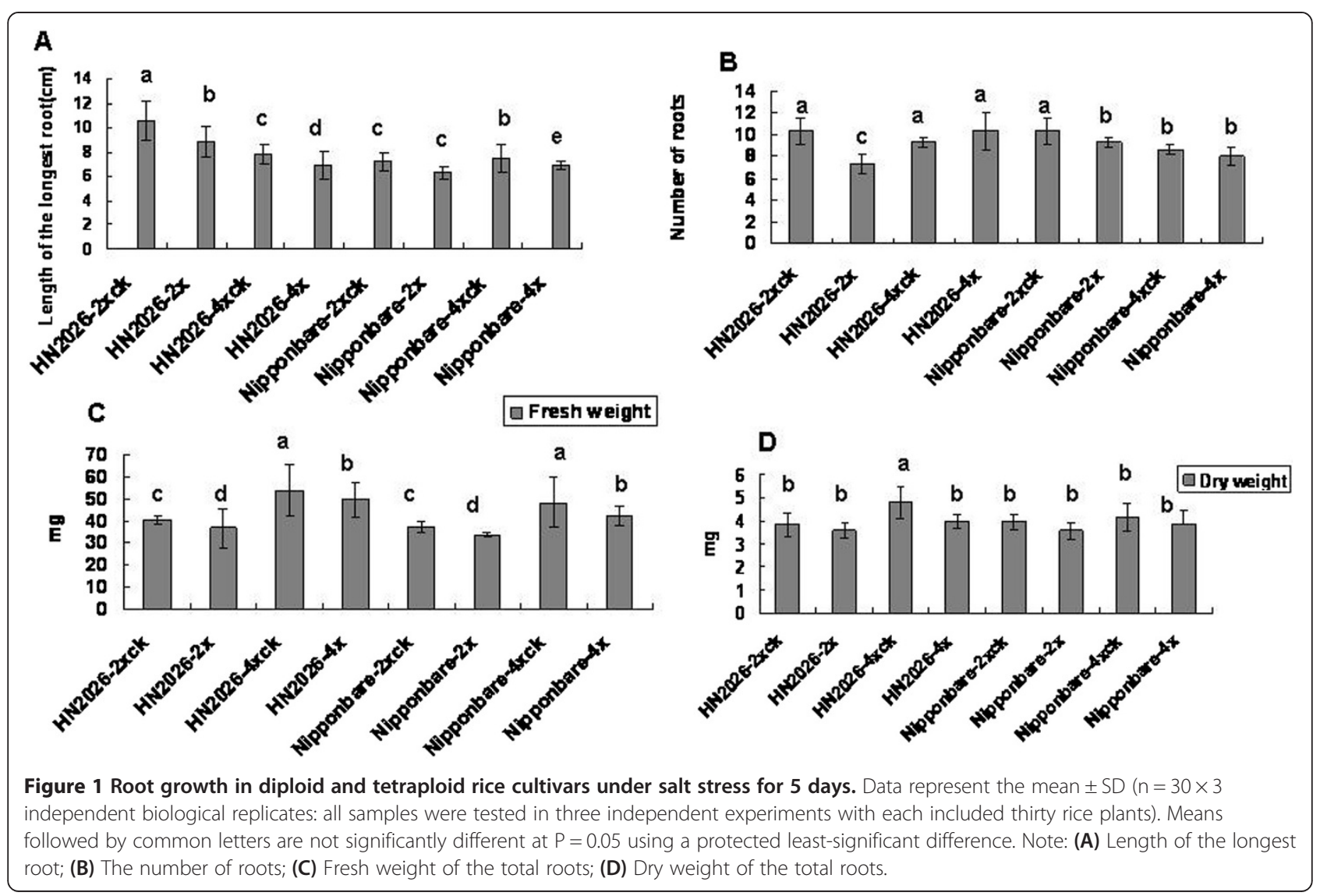




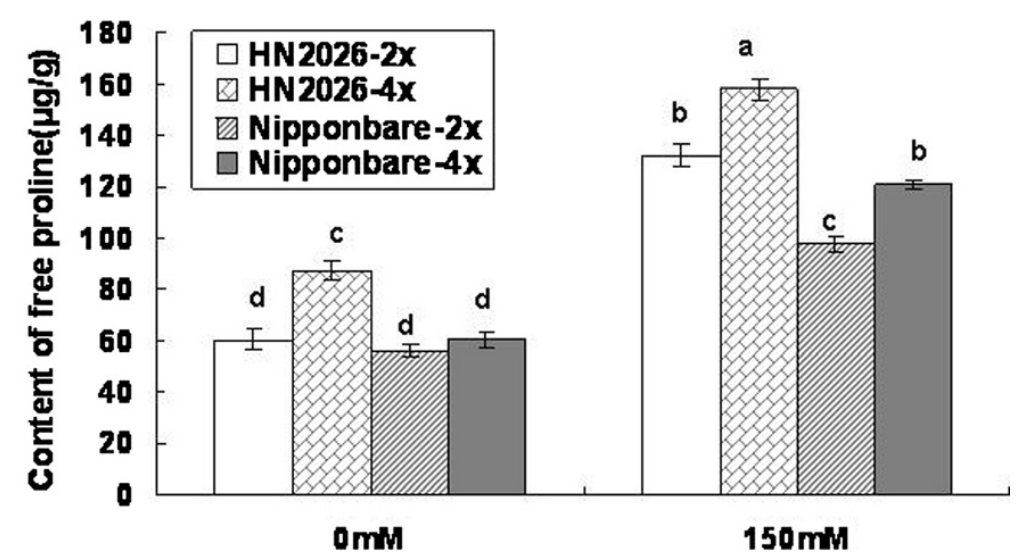

Figure 2 Amount of free proline in roots of diploid and tetraploid rice under salt stress. Data represent the mean $\pm S D(n=30 \times 3$ independent biological replicates:all samples were tested in three independent experiments with each included thirty rice plants). Means followed by common letters are not significantly different at $P=0.05$ using a protected least-significant difference.

132.09 and $98.12 \mu \mathrm{g} \mathrm{g}^{-1}$, respectively. Free proline accumulation was highest in HN2026-4x (157.91 $\left.\mu_{\mathrm{g} \mathrm{g}} \mathrm{g}^{-1}\right)$ and reached $120.99 \mu \mathrm{g} \mathrm{g}^{-1}$ in Nipponbare-4x. However, the increase in free proline in Nipponbare-4x compared with Nipponbare-2x was $23.30 \%$. In addition, the increase in $\mathrm{HN} 2026-4 \mathrm{x}$ was $19.55 \%$.

\section{Accumulation of soluble sugar in roots of diploid and tetraploid rice cultivars}

Genome duplication led to a similar increase in different rice cultivars in terms of soluble sugar accumulation under salt stress, and the difference was significant between tetraploid and diploid rice subjected to salt stress. However, no significant changes were found between the two different cultivars for tetraploid or diploid rice (Figure 3). The amount of soluble sugar in tetraploid rice roots was similar to that of the corresponding diploid cultivars under normal conditions, but showed a marked decrease in the tetraploid rice roots compared with diploid cultivars under salt stress.
The content of malondialdehyde in roots of diploid and tetraploid rice cultivars under salt stress

Malondialdehyde (MDA) accumulated to similar levels in all rice cultivars tested, and no significant difference was detected between diploid and tetraploid rice cultivars without salt stress. However, the amount of MDA in the roots of various rice cultivars under salt stress was significantly greater than in the control (Figure 4). In contrast, the amount of MDA in the roots of tetraploid rice under salt stress was significantly lower than that in diploid cultivars, suggesting that membrane integrity was higher in tetraploid cultivars than in diploid rice (Figure 4). Genotypes Nipponbare-4x

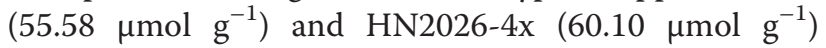
accumulated less MDA in their roots compared to the corresponding diploid cultivars under normal condition. Under salt stress, the amount of MDA in HN2026-4x conditioned with salt was lowest among all cultivars (Figure 4).

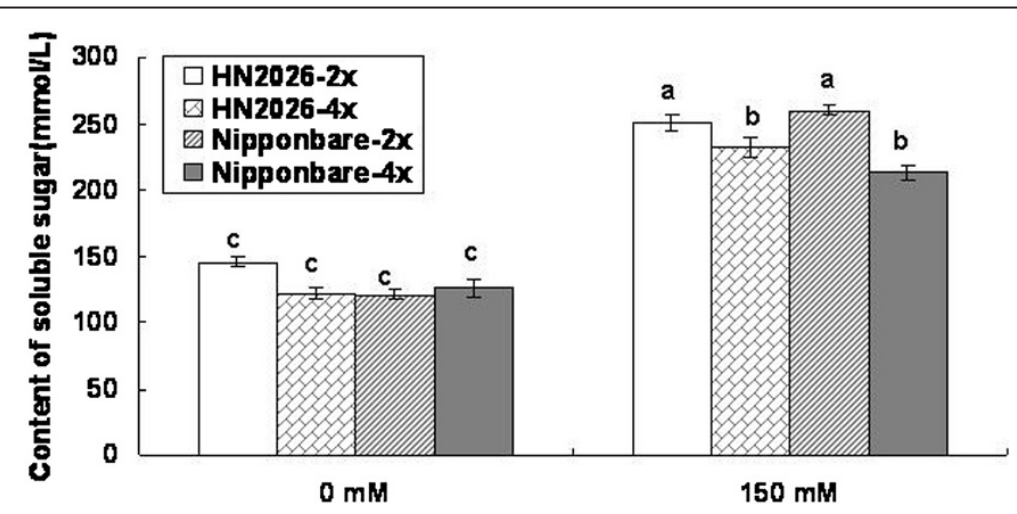

Figure 3 The amount of soluble sugar in roots of diploid and tetraploid rice under salt stress. Data represent the mean \pm SD ( $n=30 \times 3$ independent biological replicates: all samples were tested in three independent experiments with each included thirty rice plants). Means followed by common letters are not significantly different at $\mathrm{P}=0.05$ using a protected least-significant difference. 


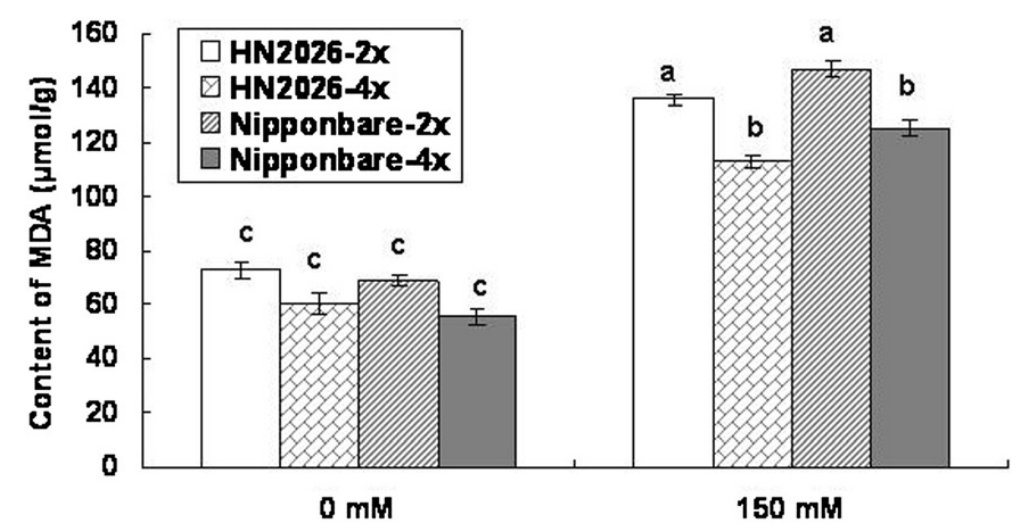

Figure 4 The accumulation of MDA in roots of diploid and tetraploid rice under salt stress. Data represent the mean $\pm S D(n=30 \times 3$ independent biological replicates: all samples were tested in three independent experiments with each included thirty rice plants). Means followed by common letters are not significantly different at $\mathrm{P}=0.05$ using a protected least-significant difference.

\section{Anatomical structure of roots in diploid and tetraploid rice under salt stress}

To increase our understanding of the root response in polyploid rice, the anatomical structure of roots in Nipponbare-2x and $-4 x$ cultivars were observed on plants under salt stress for 3 and 5 days because Nipponbare-4x was thought to be more resistant to salt. Histological analysis indicated that genome duplication regulated the root response to salt stress. The root microstructure in diploid and tetraploid rice was similar without salt stress, and no evident morphological differences in the epidermis, cortex, vascular system, or aerenchyma were observed to facilitate oxygen transport. However, the diameter of the longest root in tetraploid rice was larger than that in the corresponding diploid (Figure 5A, A1, D). Following 3 days of stress at $150 \mathrm{mM} \mathrm{NaCl}$, evident epidermis cell transfigurations were detected in Nipponbare-2x. For example, it became thinner and $57.89 \%$ of roots showed some epidermis cells that were shelled. However, $82.75 \%$ of the investigated roots indicated the epidermis cells in Nipponbare-4x maintained the normal framework and became thicker (Figure 5B, B1, E). Continuous morphological analysis after the root was exposed to $150 \mathrm{mM} \mathrm{NaCl}$ for 5 days revealed distinct differences between diploid and tetraploid rice (Figure $5 \mathrm{C}, \mathrm{C} 1$ ). The roots in Nipponbare-2x shrank and became transfigured because of the extended water absence under salt stress; $78.54 \%$ of epidermis cells in the investigated roots brushed off and more aerenchyma tissues were produced by the cortex cells compared to 3-day roots under salt stress(Figure 5E). In addition, the pericycle cells shrank (Figure 5C, E), while in the roots of Nipponbare-4x, only $22.34 \%$ of epidermis cells separated from the cortex cell. Obvious thicker epidermis cells were in tight contact, and endo-epidermis formed a thicker barrier protected from the aerenchyma damage and blocked deleterious ion transport to pericycle cells. The protective gap produced between the cortex cells and pericycle cells, as well as the neighboring cells of pericycle cells, were thicker, which was considered the second barrier for the root in Nipponbare-4x. The root response in HN2026-2x and HN2026-4x was similar to Nipponbare-2x and Nipponbare-4x, respectively (data not shown).

\section{$6<\mathrm{H} 2>$ Ultrastructural comparison of roots in diploid and tetraploid rice under salt stress}

Ultrastructural analysis in Nipponbare-2x and $-4 x$ cultivars roots under $150 \mathrm{mM} \mathrm{NaCl}$ stress for 3 and 5 days showed that genome duplication improved rice adaptability, including the epidermis cell protective mechanism, membrane organelle, and nuclei stability. The epidermis cells with abundant cytoplasm accumulation around the cell wall were closely connected in diploid and tetraploid rice without salt treatment (Figure 6A, A1). After treatment with $\mathrm{NaCl}$ for 3 days, the cell wall of the epidermis cells became loose, and some exterior parts of the epidermis cell wall were isolated and desquamated in Nipponbare-2x (Figure 6B). However, in Nipponbare-4x, the epidermis cell wall became thicker and a barrier formed around the epidermis cells (Figure 6B, B1). A significant difference was observed for the cortex cells between Nipponbare-2x and Nipponbare-4x. Floccules were discovered between the cortex cells in Nipponbare- $2 x$ (Figure 6C), which was not observed in Nipponbare-4x (Figure $6 \mathrm{Cl}$ ). Membrane organelles showed an evident transfiguration in the pericycle cells of Nipponbare-2x (Figure 6D). In contrast, cells maintained their normal shape surrounded by cytoplasm in Nipponbare-4x (Figure 6D1). After $\mathrm{NaCl}$ treatment for 5 days, nuclei with an abnormal shape and floccule nuclear cytoplasm were observed in the pericycle cells of Nipponbare-2x (Figure 6E). However, nuclei with intact membranes, 


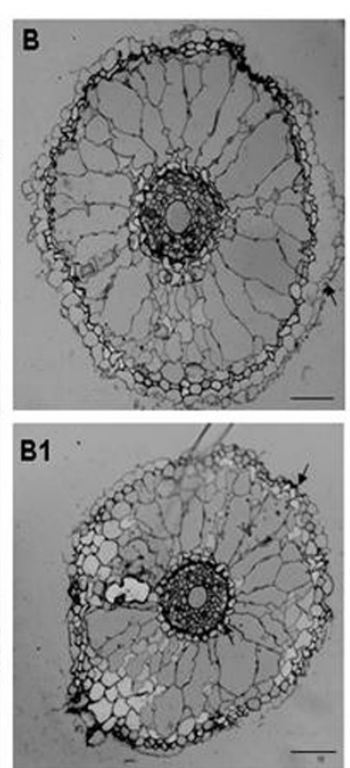
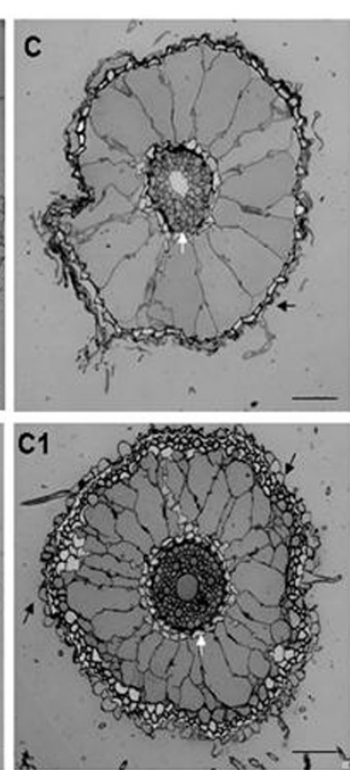

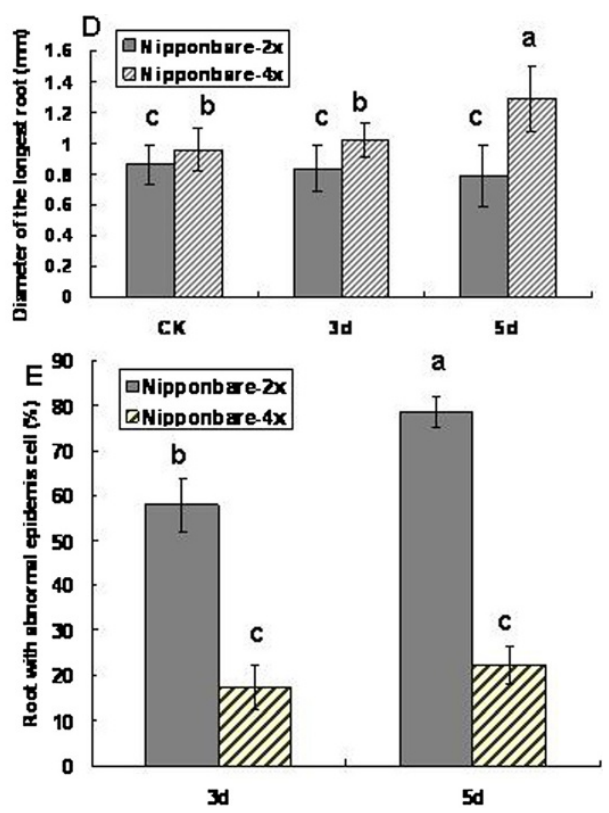

Figure 5 The longest root microstructure, diameter, and abnormal epidermis frequency of Nipponbare-2x and Nipponbare-4x under salt stress $($ Bar $=\mathbf{5 0} \boldsymbol{\mu m}$ ). (A) Roots of Nipponbare-2x under normal conditions. (A1) Roots of Nipponbare-4x under normal conditions. (B) Root of Nipponbare-2x under salt stress for 3 days, whereby the black arrows show the epidermis cells abnormally shelled. (B1) Root of Nipponbare-4x under salt stress for 3 days, whereby the epidermis cells maintained a normal station and the black arrow shows regularly thicker endodermis cells. (C) Roots of Nipponbare-2x under salt stress for 5 days, whereby the root shrank and transfigured; the black arrow suggests that the epidermis became thinner. (C1) Root of Nipponbare-4x under salt stress for 5 days, whereby the protective gap formed between the cortex cells and pericycle cells (white arrow) and the epidermis cells became much thicker (black arrow) and were in close contact with each other. (D) Diameter of the longest root; (E) Frequency of roots with abnormal epidermis cells under salt stress.


Figure 6 Root ultrastructure of Nipponbare-2x and Nipponbare-4x under salt stress (Bar in $E=0.2 \mu \mathrm{m}$; others bars $=0.5 \mu \mathrm{m}$ ). (A) The epidermis cells with abundant cytoplasm (arrow) in the diploid without $\mathrm{NaCl}$ treatment. (A1) The epidermis cells in tetraploid rice were similar to the diploid under normal conditions. Arrow indicates abundant cytoplasm. (B) After $\mathrm{NaCl}$ treatment for 3 days the cell wall of the epidermis cells became loose (arrow). (B1) The cell wall of epidermis cells in Nipponbare-4x became thicker and formed a barrier around the cells (arrow). (C) Floccules (arrow) were discovered between the epidermis cells in Nipponbare-2x. (C1) The epidermis cells were normal in Nipponbare-4x, and the arrow shows normal abundant cytoplasm. (D) Membrane organelles were indicative of evident transfiguration (arrow) in the pericycle cells of Nipponbare-2x. (D1) Pericycle cells maintained a normal shape surrounded by cytoplasm (arrow) in Nipponbare-4x. (E) The nuclei with an abnormal shape, whereby floccule nuclear cytoplasm was observed in the pericycle cells of Nipponbare-2x (arrow). (E1) Nuclei with intact membrane (arrow) and dispersed chromatins were observed in pericycle cells of Nipponbare-4x. 

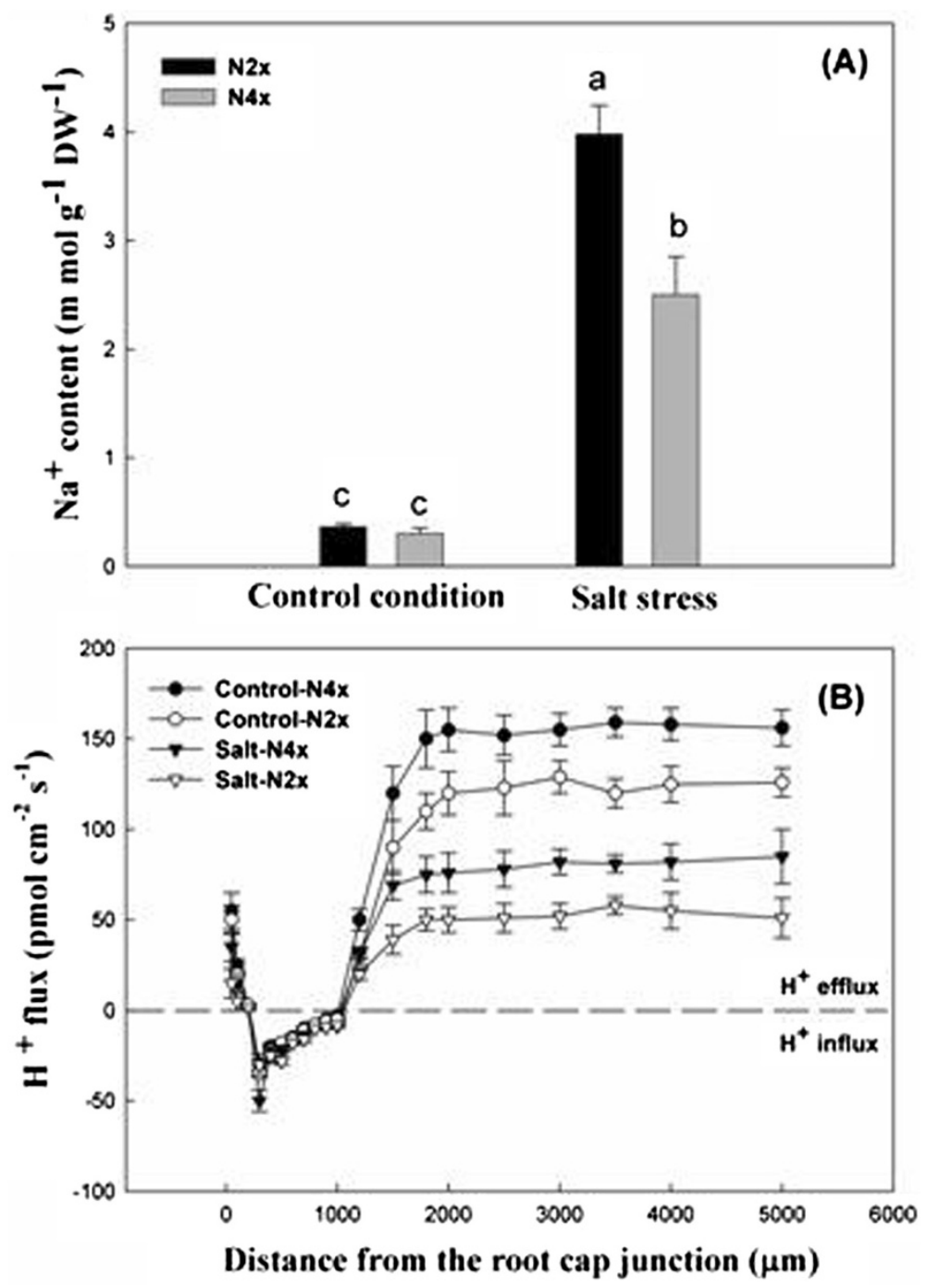

Figure $7 \mathrm{Na}^{+}$content and $\mathrm{H}^{+}$flux of Nipponbare-2x and $-4 x$ under salt stress. (A) $\mathrm{Na}^{+}$content in Nipponbare-2x and $-4 x$. (B) $\mathrm{H}^{+}$flux in Nipponbare-2x and $-4 x$.

smooth surfaces, and dispersed chromatin were observed in Nipponbare-4x (Figure 6E1). These results indicated that genome duplication promoted roots to show normal active metabolism.

\section{$\mathrm{Na}^{+}$content and $\mathrm{H}^{+}$flux in diploid and tetraploid rice under salt stress}

The $\mathrm{Na}^{+}$content in the whole plant including the root and shoot was measured using inductively coupled plasma emission spectroscopy (ICP-AES)( Figure 7A). The results clearly indicated that $\mathrm{Na}^{+}$accumulation in Nipponbare-2x and Nipponbare-4x did not differ from control conditions, whereas $\mathrm{Na}^{+}$content in Nipponbare-2x increased significantly compared to Nipponbare- $4 x$ under salt stress. This low level of $\mathrm{Na}^{+}$content suggested that Nipponbare$4 \mathrm{x}$ had a better protective effect against deleterious ions, leading to higher salt tolerance. $\mathrm{H}^{+}$efflux and influx were detected in the roots of Nipponbare-2x and Nipponbare$4 \mathrm{x}$, which was demonstrated $500 \mu \mathrm{m}$ from the root tip (Figure 7B). We observed that $\mathrm{H}^{+}$efflux or influx in Nipponbare-2 $x$ and Nipponbare- $4 x$ did not differ between control and treated conditions. At $500-1000 \mu \mathrm{m}$ from the root tip, $\mathrm{H}^{+}$influx was dominant, which was similar in diploid and tetraploid rice. However, $\mathrm{H}^{+}$efflux increased gradually as distance increased to $1000-2000 \mu \mathrm{m}$ from the root tip, which was higher in Nipponbare- $4 x$ than in Nipponbare-2x under both control conditions and salt stress. Subsequently, $\mathrm{H}^{+}$efflux entered into the stable stage beyond $2000 \mu \mathrm{m}$ from the root tip, and a striking difference was observed between $\mathrm{H}^{+}$efflux in Nipponbare-4x and Nipponbare-2x under salt treatment. The high $\mathrm{H}^{+}$ efflux was indicative of low $\mathrm{pH}$ in Nipponbare-4x. 


\section{Discussion}

Salinity is an important environmental factor limiting the productivity of crop plants because most crop plants are sensitive to high concentrations of $\mathrm{Na}^{+}$in the soil (Munns and Tester 2008; Ahmad and Prasad 2012; Hasanuzzaman et al. 2013). Salinity at higher levels caused both hyperionic and hyperosmotic stress, and resulted in a series of adverse effects that ultimately resulted in plant death (Mahajan and Tuteja 2005; Hasanuzzaman et al. 2012; Brini and Masmoudi 2012). As we know, osmotic stress was beginning at the early phase under salt stress, and then ionic stress was started at the latter stress phase (Greenway and Munns 1980; Al-Khayri and Al-Bahrany 2002; Yamada et al. 2005; Jayasekaran et al. 2006; Munns and Tester 2008; Krishnamurthy et al. 2009; Szabados and Savouré 2010). The rice roots, which are in direct contact with the soil, must tolerate osmotic and ionic stress under saline conditions (Smet et al. 2012). Osmotic stress in plants occurs immediately with an increase in salt levels outside the roots, which inhibits water uptake, cell expansion, and lateral bud development (Steudle 2000; Munns 2002; Ranathunge et al. 2003; Ranathunge et al. 2005; Munns and Tester 2008). On the other hand, salt-induced oxidative stress may disrupt the membrane structure since the overproduction of reactive oxygen species triggers lipid and protein peroxidation ((Dionisio-Sese and Tobita 2000); Radic et al. 2006; (Moller et al. 2007; Ahmad et al. 2009; Azevedo et al. 2009)). Our results indicated that the amount of free proline in the roots of tetraploid rice was siginificantly higher than that in corresponding diploid cultivars, however, the amount of MDA in roots of all tetraploid rice cultivars was markedly less than that in the diploid cultivars, which suggests that tetraploid rice can maintain membrane integrity under salt treatment. Thus, we proposed that the differences among proline and MDA between tetraploid rice and diploid rice may contribute to salt-tolerance in early-salt-stress response and help to combat with later-salt-stress response in rice.

The ionic stress phase develops later when toxic ions such as $\mathrm{Na}^{+}$accumulate in plants, particularly when transport from root to leaves is over the threshold ((Yeo and Flowers 1986); Glenn and Brown 1999; Zhu 2002). Roots are thought to cope with ionic stress during high salt treatment by adapting their structures, and determining how roots avoid the influx of excess salt is important. $\mathrm{Na}^{+}$translocation from the root to the shoot is an important issue in salt-stress physiology ((Flowers et al. 1977); Läuchli 1984; (Tester and Davenport 2003; Krishnamurthy et al. 2009; Krishnamurthy et al. 2011)). Based on earlier physiological and morphological studies, the initial uptake of solutes is generally believed to occur at the epidermis or exodermis, or if soil solution flows apoplastically across the root cortex, the endodermis (Enstone et al. 2003). In most plants, radial transport of $\mathrm{Na}^{+}$into the root xylem occurs through a cell-to-cell pathway involving xylem loading transporters (Munns 2002). However, in rice, considerable apoplastic bypass flow of $\mathrm{Na}^{+}$into the stele has been observed (Yeo et al. 1987; Yadav et al. 1996; Garcia et al. 1997; Gong et al. 2006), which is regulated by $\mathrm{Ca}^{2+}$ to varying degrees among different rice cultivars (Anil et al. 2005). Casparian bands of the endodermis and exodermis play crucial roles in blocking apoplastic movement of ions and water into the stele of roots through the cortex (Steudle and Peterson 1998; Schreiber et al. 1999; Schreiber et al. 2005). In this study, to explore the detailed resistance mechanisms to salinity stress in rice roots, the anatomical structure and ultrastructure of roots in Nipponbare-2 $\mathrm{x}$ and $-4 \mathrm{x}$ were investigated in plants under salt stress. Our results suggest that epidermis cells in Nipponbare-4x maintained the normal framework after 3 days of salt treatment and showed thicker cell walls of some cortex cells, resulting in the formation of a barrier block near the epidermis. However, in the epidermis of Nipponbare-2x, a series of abnormal changes (such as becoming thinner and cellular distortion) were observed. Continuous root morphological analysis after $150 \mathrm{mM} \mathrm{NaCl}$ treatment for 5 days suggested that epidermis cells in Nipponbare-4x became thicker as the first protective barrier against $\mathrm{Na}^{+}$. As a protective gap between the cortex cells and pericycle cells, it may be the second protective barrier for the root of tetraploid rice under salt stress. Based on subsequent ultrastructure detection, membrane organelles maintained their normal shape surrounded by cytoplasm under the high salt treatment in Nipponbare-4x. This hypothesis agreed with other previous results, which indicated that excess salts adversely affect all major metabolic activities in rice including cell wall damage, accumulation of electron-dense proteinaceous particles, plasmolysis, cytoplasmic lysis, and endoplasmic reticulum (ER) damage (Steudle and Heydt 1997; Barrowclough et al. 2000; Miyamoto et al. 2001; Lee et al. 2005). However, our results confirmed that $\mathrm{Na}^{+}$content in Nipponbare-2x significantly increased compared with that in Nipponbare- $4 x$ under salt stress. The low level of $\mathrm{Na}^{+}$content suggested that Nipponbare- $4 \mathrm{x}$ experienced a faint absorption of deleterious ions. We speculated that the anatomical structure and ultrastructure of roots in Nipponbare- $4 x$ may play critical roles in counteracting ionic stress at the latter phase under salt stress. Polyploidy can alter plant morphology, phenology, and physiology, increasing plant tolerance to fluctuating environments (Adams and Wendel 2005). We next explored which factor resulted in Nipponbare-4x salt stress resistance by characterizing the cellular and molecular mechanisms. Several categories of regulatory function and transporter activity were 
over-duplicated, and the complexity of regulatory networks and adaptability to changing environmental conditions would be increased in polyploidy (Osborn et al. 2003; Blanc and Wolfe 2004; Saleh et al. 2008). Adaptation to stress by high salt content may also occur through gene duplication, and polyploidy has been associated with resistance to high salt concentrations in Citrus and Sorghum. Polyploidy has been suggested to be a general physiological adaptive response to osmotic stress ((Ceccarelli et al. 2006; Gerstein et al. 2006; Saleh et al. 2008); Dhar et al. 2011). Polyploidy was advantageous because of the increased vigor compared with diploid and tetraploid relatives and its ability to produce diverse gene products under stress environments (Comai 2005). However, how polyploid rice increases salt stress tolerance is complicated and requires further study.

Furthermore, under salt stress, the pumping activity of the plasmalemma $\mathrm{H}^{+}$-ATPase is inhibited and may contribute to a weaker acidification of the apoplast, and thus to growth inhibition (Maeshima 2001; (Mariko et al. 2009; Xu et al. 2013)). $\mathrm{Na}^{+}$sequestration into the vacuole depends on the expression and activity of the $\mathrm{Na}^{+} / \mathrm{H}^{+}$ antiporter that is driven by an electrochemical gradient of protons generated by the vacuolar $\mathrm{H}^{+}$-ATPase and $\mathrm{H}$ ${ }^{+}$-pyrophosphatase (Fuglsang et al. 2011; Brini and Masmoudi 2012). The cell wall extensibility is reduced under salt stress due to the inhibition of pumping activity of the plasmalemma $\mathrm{H}^{+}$-ATPase (Zörb et al. 2005). At a $2000 \mu \mathrm{m}$ distance from the root cap, $\mathrm{H}^{+}$efflux becomes the dominant form with stable values, and Nipponbare- $4 \mathrm{x}$ was significantly higher than Nipponbare-2x under salt treatment. The plasmalemma- $\mathrm{H}^{+}$-ATPase acidifies the apoplast by pumping protons out of the cell, and the decreased $\mathrm{pH}$ activates cell wall-loosening enzymes that break bonds in the cell wall and enables turgor to drive cell elongation (Michelet and Boutry 1995; Palmgren 1998; Gaxiola et al. 2002; Cosgrove 2005; Gaxiola et al. 2007). The high $\mathrm{H}^{+}$efflux in tetraploid rice leading to low $\mathrm{pH}$ conditions may contribute to faster root growth, but the length, fresh weight, and dry weight of the root were restricted in diploid cultivars compared to tetraploid rice under salt stress.

Salt stress induces various complex biochemical, molecular, cellular, and physiological changes in plants (Atkinson and Urwin 2012; Horie et al. 2012). Previous studies have shown that abiotic stress conditions have considerable effects on duplicate gene expression in polyploids, with the effects varying in relation to gene, stress, and organ (Blanc and Wolfe 2004). Differential expression in response to environmental stress may play a role in the preservation of some duplicated genes in polyploidy (Blanc and Wolfe 2004). Recent molecular, physiological, and molecular genetic studies have increased our understanding on the protection mechanisms that plants use to cope with detrimental effects of salinity stress ((Blumwald 2000); Zhu 2002; (Munns 2005; Ren et al. 2005; Munns and Tester 2008; Horie et al. 2009); Hauser et al. 2010). Correlations between the ploidy levels and morphological traits in wheat were significantly positive under saline conditions, showing that values of morphological traits increased with the number and types of genomes. Polyploidy was significantly associated with the species performance for all traits in the study, excluding the number of yellow leaves and shoots under saline conditions (Rauf et al. 2010). The expression of genes duplicated by polyploidy (termed homeologs) in cotton can be partitioned between the duplicates so that one copy is expressed and functions only in some organs, and the other copy is expressed only in other organs, indicative of subfunctionalization. These results suggest that the subfunctionalization of genes duplicated by polyploidy occurred in response to abiotic stress conditions. Partitioning of duplicate gene expression in response to environmental stress may lead to duplicate gene retention during subsequent evolution (Liu and Adam 2007). As several sources of improved $\mathrm{Na}^{+}$ "exclusion" are now known to reside on different chromosomes in various genomes of species in the Triticeae, further studies are required to identify the underlying mechanisms controlling genes for the various traits that could act additively or even synergistically, which may enable substantial gains in salt tolerance (Colmer et al. 2006). The regulation mechanism is complicated in polyploid rice, and understanding how duplicated genes affect rice development under salt stress could be important for biological and agricultural applications. The results of our work suggest that tetraploid rice has a better protective mechanism than diploid rice against salinity, in agreement with the results of earlier studies on the genome duplication effect in Citrus, Acanthophyllum spp., and other plants under salt stress (Saleh et al. 2008; Yildiz and Terzi 2008; Mouhaya et al. 2010). Several studies have indicated that the response of plant cells to high salt is controlled by multiple genes (Bartels and Sunkar 2005; Chinnusamy et al. 2005; Sahi et al. 2006). Polyploid rice was believed to improve the root adaptability to salt stress by regulating root growth and protective structure formation, subsequently decreasing $\mathrm{Na}^{+}$assimilation. Thus, exploring the significance of protection mechanisms in polyploid rice salt tolerance, including morphological barriers at the molecular, cellular, and whole plant level, is important to develop high-yielding, salt-tolerant polyploid cultivars.

\section{Conclusions}

Rice is a very important and salt-sensitive crop. Previous reports have suggested that polyploid rice has some 
superiority in stress resistance. However, few studies have focused on the effect of genome duplication on rice root response under salt stress. The objective of this study was to investigate how genome duplication regulates the rice root response to salt stress. Our results demonstrated that salt stress significantly restricted rice root growth in both diploid and tetraploid rice, and that genome duplication improved the root growth in tetraploid rice, with faster and better root growth in the presence of $150 \mathrm{mM} \mathrm{NaCl}$. Free proline accumulated in tetraploid rice cultivars under salt stress varied greatly, which increased compared to that in the diploid cultivars. Genome duplication significantly decreased the MDA content in tetraploid rice compared to diploid cultivars subjected to salt stress, which suggests that the membrane integrity improved in the tetraploid compared to the diploid. Investigation of the anatomical structure of roots under salt stress showed a high frequency of epidermis cells maintaining their normal structure, and a gap appeared between the cortex and pericycle cells in tetraploid rice roots. These protective mechanisms improved the root adaptability to salt stress. Ultrastructural analysis showed that genome duplication also improved the root response, including the epidermis cell protective mechanism formation, and membrane organelle and nuclei stability. Anatomical structure and ultrastructure of roots in Nipponbare-4x may play critical roles in counteracting $\mathrm{Na}^{+}$absorption, and $\mathrm{Na}^{+}$content in Nipponbare-2x greatly increased compared to that in Nipponbare-4x under salt stress. The high $\mathrm{H}^{+}$efflux in tetraploid rice led to low $\mathrm{pH}$ conditions and may have contributed to increased root growth, the length of the root, and the fresh and dry weights of the root, which were restricted in the diploid compared to the tetraploid under salt stress. Overall, our results suggest that genome duplication improved root resistance to salt stress and enhanced proton transport to the root surface, which may play a role in reducing $\mathrm{Na}^{+}$entry into the roots.

\section{Methods}

\section{Plant materials and growth conditions}

HN2026-2 $x$ and $-4 x$ and Nipponbare- $2 x$ and $-4 x$ were used in this study. The tetraploid rice cultivars were cultured according to our patent and as described previously (Cai et al. 2004). Seeds were germinated on moist tissue paper at $28^{\circ} \mathrm{C}$ in the dark for 2-3 days. Seedlings were transferred to half-strength Murashige and Skoog ( $1 / 2$ MS) medium (Murashige and Skoog 1962) in containers. The seedlings were allowed to grow for 20 days post-germination with continuous media aeration at $28^{\circ} \mathrm{C}$ illuminated at $450 \mu \mathrm{mol} \mathrm{m} \mathrm{m}^{-2} \mathrm{~s}^{-1}$ using fluorescent lighting with a day and night cycle of $12 \mathrm{~h}$ each. Seedlings were then cultured in $1 / 2 \mathrm{MS}$ medium (Murashige and Skoog 1962) with $150 \mathrm{mM} \mathrm{NaCl}$.

\section{Measument of root growth under salt stress}

We choosed the longest root (primary root as noted in (Xu et al. 2013)) of every plant to measure the length, and weighed the fresh and dry weight of total root with precision electronic autobalance, and recorded the total root numbers. The diameter of the longest root was measured by vernier caliper. All samples were tested in three independent experiments with each included thirty rice plants.

\section{Extraction of free proline}

The proline content in roots in the presence of $150 \mathrm{mM}$ $\mathrm{NaCl}$ for 5 days was investigated. The free proline content was extracted and quantified using the acid ninhydrin method as described by Bates et al. (Bates et al. 1973). The content of free proline was calculated using the standard curve. All samples were tested in three independent experiments with three replicates each.

\section{MDA content}

The content of MDA in roots subjected to $150 \mathrm{mM} \mathrm{NaCl}$ for 5 days was calculated. The method was in accordance with the results of Hodges et al. (Hodges et al. 1999). Briefly, $0.5 \mathrm{~g}$ of fresh rice roots was homogenized with $5 \mathrm{ml}$ of $5 \%(\mathrm{v} / \mathrm{v})$ 2,4,6-trichloroanisole, and then centrifuged at $3000 \mathrm{rpm}$ for $10 \mathrm{~min}$. The supernatant was mixed with $2 \mathrm{ml}$ of $0.67 \%(\mathrm{v} / \mathrm{v})$ 2,4,6-tribromoanisole, boiled for $30 \mathrm{~min}$, and then cooled and centrifuged again. The absorbance (A) of the supernatant at $532 \mathrm{~nm}, 600 \mathrm{~nm}$, and $450 \mathrm{~nm}$ was measured and the MDA content $(C)$ was calculated as follows: $\mathrm{C}\left(\mu \mathrm{mol} \mathrm{L}{ }^{-1}\right)=6.45\left(\mathrm{~A}_{532}-\mathrm{A}_{600}\right)-$ $0.56 \mathrm{~A}_{450}$. All samples were tested in three independent experiments with three replicates each.

\section{Soluble reducing sugar content}

The soluble reducing sugar content in roots exposed to salt treatment for 5 days was measured as described previously (Ranney et al. 1991). Briefly, $0.1 \mathrm{~g}$ of fresh rice roots was homogenized with $5 \mathrm{ml}$ of distilled water and then centrifuged at $8000 \mathrm{rpm}$ for $10 \mathrm{~min}$. The soluble reducing sugar content was measured as follows: $1.0 \mathrm{ml}$

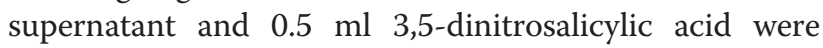
mixed, heated in boiling water for $5 \mathrm{~min}$, and cooled. The absorbance was measured at $520 \mathrm{~nm}$, and the amount of reducing sugar was calculated from the standard curve. All samples were tested in three independent experiments with three replicates each.

\section{Anatomical analysis of roots}

Rice roots exposed to salt treatment for 3 and 5 days were dissected and vacuum-infiltrated with $3 \%(\mathrm{w} / \mathrm{v})$ paraformaldehyde (Sigma, St. Louis, MO, USA) and $0.25 \%$ glutaraldehyde (Sigma) in phosphate-buffered saline (PBS) for $30 \mathrm{~min}(\mathrm{pH}$ 7.2). The fixed roots were 
renewed with fresh solution and post-fixed in $1 \% \mathrm{OsO}_{4}$ (Sigma) in PBS (pH 7.2). The tissues were washed in PBS, dehydrated in a graded ethanol series, and embedded in EPON812 (Emicron, http://www.instrument. com.cn/). Half-thin sections $(100 \mathrm{~nm})$ were examined at every stage, and observations and photographic recordings were performed with a BX51 microscope (Olympus, Tokyo, Japan). Ultrathin sections (50-70 $\mathrm{nm})$ were double-stained with $2 \%(\mathrm{w} / \mathrm{v})$ uranyl acetate (Sigma) and 2.6\% (w/v) lead citrate (Sigma) aqueous solution and examined with a transmission electron microscope (H-8100; Hitachi, Tokyo, Japan) at $100 \mathrm{kV}$.

\section{Measurement of $\mathrm{Na}^{+}$concentration}

After seedlings were cultured in $1 / 2$ MS medium (Murashige and Skoog 1962) with $150 \mathrm{mM} \mathrm{NaCl}$ for 5 days, whole plants including shoots and roots were collected and dried at $70^{\circ} \mathrm{C}$ for at least 3 days, after which they were weighed. Samples were digested with $\mathrm{HNO}_{3}$ and the concentration of $\mathrm{Na}^{+}$was determined using ICP-AES (IRIS Advantage; Thermo Electron, Waltham, MA, USA). All samples were tested in three independent experiments with three replicates each.

\section{Assay of $\mathrm{H}^{+}$flux in the rice root tip}

$\mathrm{H}^{+}$fluxes were measured noninvasively using SIET (SIET system BIO-003A; YoungerUSA Science and Technology Corporation, Amherst, MA, USA). Rice plants were equilibrated in measuring solution for $20-30 \mathrm{~min}$, and these equilibrated rice plants were transferred to the measuring chamber, which was a small plastic dish (3 cm diameter) containing $2-3 \mathrm{ml}$ of fresh measuring solution. When the root became immobilized at the bottom of the dish, the microelectrode was vibrated in the measuring solution between two positions ( $5 \mu \mathrm{m}$ and $35 \mu \mathrm{m}$ from the root surface) along an axis perpendicular to the root. The background was recorded based by vibrating the electrode in measuring solution not containing roots. The microelectrode was made and silanized by Xuyue Science and Technology Co., Ltd. (Beijing, China). All samples were tested in three independent experiments with three replicates each.

\section{Statistical analysis}

All values are shown as the mean of five replicates, and the average was calculated. The results were analyzed for variance using the SAS/STAT statistical analysis package (version 6.12; SAS Institute, Cary, NC, USA) to determine significant differences. Means followed by common letters are not significantly different at $\mathrm{P}=0.05$ using a protected least-significant difference.

\section{Competing interests}

The authors declare that they have no competing interests.

\section{Authors' contributions}

Yi Tu and Aiming Jiang contribute equally to this paper, they cooperted to finish all experiments. Lu Gan, Md. Mokter Hossain and Jinming Zhang made contribution of making figure and table. Bo Peng, Yuguo Xiong and Zhaojian Song were responsible for materails planting, nursing and data analysis. Detian Cai and Jianhua Zhang gave this research important guidance and revised the manuscript. Yuchi He and Weifeng Xu cooperated to design the the whole research and write the manuscript, they are sharing the corresponding person for giving final approval of the version to be submitted. All authors read and approved the final manuscript.

\section{Acknowledgements}

This project was supported by the Chinese National Natural Science Foundation (31270356, 31271690), National Basic Research Project (Nos.2014CB954500, 2013CB127402 and 2012CB114300), the strategic leading special science and technology project of Chinese Academy of Sciences (XDB15030201), Hubei Important Natural Science Foundation (2013CFA028) and Hubei Province Department of education foundation (D20120103, Q20131006).

\section{Author details}

${ }^{1}$ Hubei Collaborative Innovation Center for Green Transformation of Bio-Resources, Hubei University, Wuhan 430062, P.R. China. ${ }^{2}$ School of Life Sciences and State Key Laboratory of Agrobiotechnology, The Chinese University of Hong Kong, Hong Kong, China. ${ }^{3}$ State Key Laboratory of Soil and Sustainable Agriculture, Institute of Soil Science, Chinese Academy of Sciences, Nanjing 210008, China. ${ }^{4}$ Faculty of Biochemistry and Environmental Engineering, Yunyang Teachers' College, Shiyan 442000, P.R. China.

Received: 24 January 2014 Accepted: 15 July 2014

Published online: 02 September 2014

\section{References}

Adams KL, Wendel JF (2005) Polyploidy and genome evolution in plants. Curr Opin Plant Biol 8:135-141

Ahmad F, Khan MA, Ahmad M, Zafar M, Nazir A, Marwat SK (2009) Taxonomic studies of grasses and their indigenous uses in the salt range area of Pakistan. Afri J Biotechnol 18:231-249

Ahmad P, Prasad MNV (2012) Abiotic stress responses in plants: metabolism, productivity and sustainability. Springer, New York. ISBN 1461406331

Al-Khayri JM, Al-Bahrany AM (2002) Callus growth and proline accumulation in response to sorbitol and sucrose-induced osmotic stress in rice (Oryza sativa $\mathrm{L}$ ). Biol Plantarum 45(4):609-611

Amirjani MR (2011) Effect of salinity stress on growth, sugar content, pigments and enzyme activity of rice. Int J Bot 7(1):73-81

Anil VS, Krishnamurthy P, Kuruvilla S, Sucharitha K, Thomas G, Mathew MK (2005) Regulation of the uptake and distribution of $\mathrm{Na}^{+}$in shoots of rice (Oryza sativa) variety Pokkali: role of $\mathrm{Ca}^{2+}$ in salt tolerance response. Physiol Plantarum 124(4):451-464

Atkinson NJ, Urwin PE (2012) The interaction of plant biotic and abiotic stresses: from genes to the field. J Exp Bot 63(10):3523-3543

Azevedo H, Amorim-Silva V, Tavares RM (2009) Effect of salt on ROS homeostasis, lipid peroxidation and antioxidant mechanisms in Pinus pinaster suspension cells. Ann Sci 66:211-219

Badridze G, Weidner A, Asch F, Börner (2009) Variation in salt tolerance within a Georgian wheat germplasm collection. Genet Resour Crop Evol 56:1125-1130

Baisakh N, RamanaRao MV, Rajasekaran K, Subudhi P, Janda J, Galbraith D, Vanier C, Pereira A (2012) Enhanced salt stress tolerance of rice plants expressing a vacuolar $\mathrm{H}^{+}$-ATPase subunit C1 (SaVHAc1) gene from the halophyte grass Spartina alterniflora Löisel. Plant Biotechnol J 10(4):453-464

Barrowclough DE, Peterson CA, Steudle E (2000) Radial hydraulic conductivity along developing onion roots. J Exp Bot 51(344):547-557

Bartels D, Sunkar R (2005) Drought and salt tolerance in plants. Cri Rev Plant Sci 24(1):23-58

Bates LS, Waldern RP, Teare ID (1973) Rapid determination of free proline for water stress studies. Plant Soil 39(1):205-207

Blanc G, Wolfe KH (2004) Functional divergence of duplicated genes formed by polyploidy during Arabidopsis evolution. Plant Cell 16(7):1679-1691

Blumwald E (2000) Sodium transport and salt tolerance in plants. Curr Opin Cell Biol 12(4):431-434 
Brini F, Masmoudi K (2012) Ion transporters and abiotic stress tolerance in plants. ISRN Molecular Biology: Article ID 927436, 13 pages doi:10.5402/2012/927436

Buchanan CD, Lim S, Salzman RA, Kagiampakis I, Morishige DT, Weers BD, Klein RR, Pratt LH, Cordonnier-Pratt MM, Klein PE, Mullet JE (2005) Sorghum bicolor's transcriptome response to dehydration, high salinity and ABA. Plant Mol Biol 58:699-720

Cai DT, Chen DL, Chen JG, Liu YQ (2004) A method of induction polyploidy rice with high frequency through tissue culture together with chemical agent induction. China Patent ZL01133529.7

Cai DT, Chen JG, Chen DL, Dai BC, Song Z, Yang ZF, Du CQ, Tang ZQ, He YC, Zhang DS, He GC, Zhu YG (2007) The breeding of two polyploid rice lines with the characteristic of polyploid meiosis stability. Sci China C Life Sci 50(3):356-366

Ceccarelli M, Santantonio E, Marmottini F, Amzallag GN, Cionini PG (2006) Chromosome endoreduplication as a factor of salt adaptation in Sorghum bicolor. Protoplasma 227(2-4):113-118

Chen T, Cai X, Wu X, Karahara I, Schreiber L, Lin JX (2011) Casparian strip development and its potential function in salt tolerance. Plant Signal Behav 6(10):1499-1502

Chen ZJ, Tian L (2007) Roles of dynamic and reversible histone acetylation in plant development and polyploidy. Biochim Biophys Acta 1769(5-6):295-307

Chinnusamy V, Jagendorf A, Zhu JK (2005) Understanding and improving salt tolerance in plants. Crop Sci 45:437-448

Chutipaijit S, Cha-um S, Sompornpailin K (2011) High contents of proline and anthocyanin increase protective response to salinity in Oryza sativa L. spp. indica. Aust J Crop Sci 5(10):1191-1198

Chyzhykova OA, Palladina TO (2006) The role of amino acids and sugars in supporting of osmotic homeostasis in maize seedlings under salinization conditions and treatment with synthetic growth regulators. Ukr Biokhim Zh 78(1):124-129

Colmer TD, Flowers TJ, Munns R (2006) Use of wild relatives to improve salt tolerance in wheat. J Exp Bot 57(5):1059-1078

Comai L (2005) The advantages and disadvantages of being polyploid. Nat Rev Genet 6:836-846

Cosgrove DJ (2005) Growth of the plant cell wall. Nat Rev Mol Cell Biol 6 (11):850-861

Dhar R, Sägesser R, Weikert C, Yuan J, Wagner A (2011) Adaptation of Saccharomyces cerevisiae to saline stress through laboratory evolution. J Evol Biol 24(5):1135-1153

Dionisio-Sese ML, Tobita S (2000) Effects of salinity on sodium content and photosynthetic responses of rice seedlings differing in salt tolerance. Plant Physiol 157(1):54-58

Dong SW, Adams KL (2011) Differential contributions to the transcriptome of duplicated genes in response to abiotic stresses in natural and synthetic polyploids. New Phytol 190(4):1045-1057

Enstone DE, Peterson CA, Ma FS (2003) Root endodermis and exodermis: structure, function, and responses to the environment. J Plant Growth Regul 21(4):335-351

Flowers TJ, Troke PF, Yeo AR (1977) The mechanism of salt tolerance in halophytes. Annu Rev Plant Physiol 28:89-121

Flowers TJ, Yeo AR (1981) Variability of sodium chloride resistance within rice (Oryza sativa L.) varieties. New Phytol 88:363-373

Fuglsang AT, Paez-Valencia J, Gaxiola RA (2011) Plant proton pumps: regulatory circuits involving $\mathrm{H}^{+}$-ATPase and $\mathrm{H}^{+}$-PPase. In: Geisler M, Venema $\mathrm{K}$ (eds) Transporters and Pumps in Plant Signaling., Signaling and Communication in Plants 7: 39-64

Fukuda A, Nakamura A, Tagiri A, Tanaka H, Miyao A, Hirochika H, Tanaka Y (2004) Function, intracellular localization and the importance in salt tolerance of a vacuolar $\mathrm{Na}^{(+)} / \mathrm{H}^{(+)}$antiporter from rice. Plant Cell Physiol 45(2):146-159

Garcia A, Rizzo CA, Ud-din J, Bartos SL, Senadhira D, Flowers TJ, Yeo AR (1997) Sodium and potassium transport to the xylem are inherited independently in rice, and the mechanism of sodium: potassium selectivity differs between rice and wheat. Plant Cell Environ 20(9):1167-1174

Gaxiola RA, Fink GR, Hirschi KD (2002) Genetic manipulation of vacuolar proton pumps and transporters. Plant Physiol 129(3):967-973

Gaxiola RA, Palmgren MG, Schumacher K (2007) Plant proton pumps. FEBS Lett 581(12):2204-2214

Gerstein AC, Chun HJE, Grant A, Otto SP (2006) Genomic convergence toward diploidy in Saccharomyces cerevisiae. PLoS Genet 2(9):1396-1401

Glenn EP, Brown JJ (1999) Salt tolerance and crop potential of halophytes. Crit Rev Plant Sci 18(2):227-255

Gong HJ, Randall DP, Flowers TJ (2006) Silicon deposition in the root reduces sodium uptake in rice (Oryza sativa L.) seedlings by reducing bypass flow. Plant Cell Environ 29(10):1970-1979
Gorham J, Hardy C, Wyn Jones RG, Joppa LR, Law CN (1987) Chromosomal location of a K/Na discriminating character in the $\mathrm{D}$ genome of wheat. Theor Appl Genet 74(5):584-588

Gorham J, Wyn Jones RG, Bristol A (1990) Partial characterization of the trait for enhanced $\mathrm{K}^{+}-\mathrm{Na}^{+}$discrimination in the $\mathrm{D}$ genome of wheat. Planta 180(4):590-597

Greenway H, Munns R (1980) Mechanisms of salt tolerance in nonhalophytes. Annu Rev Plant Physiol 31:149-190

Hasanuzzaman M, Fujita M, Islam MN, Ahamed KU, Nahar K (2009) Performance of four irrigated rice varieties under different levels of salinity stress. Int J Integ Biol 6(2):85-90

Hasanuzzaman M, Hossain MA, da Silva JAT, Fujita M (2012) Plant responses and tolerance to abiotic oxidative stress: antioxidant defenses is a key factors. In: Venkateswarlu B, Shanker AK, Shanker C, Mandapaka M (eds) Crop stress and its management: perspectives and strategies. Springer, Berlin, pp 261-316

Hasanuzzaman M, Nahar K, Fujita M (2013) Plant response to salt stress and role of exogenous protectants to mitigate salt-induced damages. In: Ahmad P, Azooz MM, Prasad MNV (eds) Ecophysiology and Responses of Plants under Salt Stress. Springer, New York, pp 25-87

Hauser, Horie F, Tomoaki (2010) A conserved primary salt tolerance mechanism mediated by HKT transporters: a mechanism for sodium exclusion and maintenance of high K/Na ratio in leaves during salinity stress. Plant Cell Environ 33(4):552-565

He YC, Ge J, Wei Q, Jiang AM, Gan L, Song ZJ, Cai DT (2011) Using a polyploid meiosis stability (PMeS) line as a parent improves embryo development and the seed set rate of a tetraploid rice hybrid.Can. J Plant Sci 91(2):325-335

He YC, Wei Q, Ge J, Jiang AM, Gan L, Song ZJ, Cai DT (2010) Genome duplication effects on pollen development and the interrelated physiological substances in tetraploid rice with polyploid meiosis stability. Planta 232(5):1219-1228

Hodges DM, DeLong JM, Forne CF, Prange RK (1999) Improving the thiobarbituric acid-reactive -substances assay for estimating lipid peroxidation in plant tissues containing anthoc yanin and other interfering compounds. Planta 207:604-611

Horie T, Hauser F, Schroeder JI (2009) HKT transporter-mediated salinity resistance mechanisms in Arabidopsis and monocot crop plants. Trends Plant Sci 14 (12):660-668

Horie T, Karahara I, Katsuhara M (2012) Salinity tolerance mechanisms in glycophytes: an overview with the central focus on rice plants. Rice 5:11-29

Jayasekaran K, Kim KN, Vivekanandan M, Shin JS, Ok SH (2006) Novel calcium-binding GTPase (AtCBG) involved in ABA-mediated salt stress signaling in Arabidopsis. Plant Cell Rep 25(11):1255-1262

Jiang AM, Gan L, Tu Y, Ma HX, Zhang JM, Song ZJ, Cai DT, He YC, Xue XQ (2013) The effect of genome duplication on seed germination and seedling growth of rice under salt stress. Aust J Crop Sci 7(12):1814-1821

Kavi Kishor PB, Sangam S, Amrutha RN, Sri Laxmi P, Naidu KR, Rao SSS, Rao S, Reddy KJ, Theriappan P, Sreenivasulu N (2005) Regulation of proline biosynthesis, degradation, uptake and transport in higher plants: Its implications in plant growth and abiotic stress tolerance. Curr Sci 88(3):424-438

Knäblein J, Gepstein S, Grover A, Blumwald E (2006) Producing biopharmaceuticals in the desert: building an abiotic stress tolerance in plants for salt, heat and drought. In: Knablein J, Muller RH (eds) Modern Biopharmaceuticals: Design Development and Optimization. Wiley-VCH Verlag GmbH, Weinhaum, pp 967-994

Kramer PJ, Boyer JS (1995) Water relations of plants and soil. Academic Press, Orlando, USA

Krishnamurthy P, Ranathunge K, Franke R, Prakash HS, Schreiber L, Mathew MK (2009) The role of root apoplastic transport barriers in salt tolerance of rice (Oryza sativa L.). Planta 230(1):119-134

Krishnamurthy P, Ranathunge K, Nayak S, Schreiber L, Mathew MK (2011) Root apoplastic barriers block $\mathrm{Na}^{+}$transport to shoots in rice (Oryza sativa L.). J Exp Bot 62(12):4215-4228

Krishnan A, Guiderdoni E, An G, Hsing YI, Han CD, Lee MC, Yu SM, Upadhyaya N, Ramachandran S, Zhang Q, Sundaresan V, Hirochika H, Leung H, Pereira A (2009) Mutant resources in rice for functional genomics of the grasses. Plant Physiol 149:165-170

Kronzucker HJ, Szczerba MW, Moazami-Goudarzi M, Britto DT (2006) The cytosolic $\mathrm{Na}^{+}: \mathrm{K}^{+}$ratio does not explain salinity induced growth impairment in barley: a dual-tracer study using $42 \mathrm{~K}^{+}$and $24 \mathrm{Na}^{+}$. Plant Cell Environ 29(12):2228-2237

Kronzucker HJ, Britto DT (2011) Sodium transport in plants: a critical review. New Phytol 189(1):54-81 
Läuchli A (1984) Salt exclusion: an adaptation of legumes for crops and pastures under saline conditions Salinity Tolerance in Plants. Strategies for Crop Improvement. Wiley-Interscience Publication, New York, pp 171-187

Lazof D, Cheeseman JM (1986) Sodium transport and compartmentation in Spergularia marina. Plant Physiol 81(3):742-747

Lee SH, Chung GC, Steudle E (2005) Gating of aquaporins by low temperature in roots of chilling-sensitive cucumber and chilling-tolerant figleaf gourd. J Exp Bot 56(413):985-995

Liu Z, Adam KS (2007) Expression partitioning between genes duplicated by polyploidy under abiotic stress and during organ development. Curr Biol 17:1669-1674

Lutts S, Kinet JM, Bouharmont J (1995) Changes in plant response to NaCl during development of rice (Oryza sativa L.) varieties differing in salinity resistance. J Exp Bot 46(12):1843-1852

Maeshima M (2001) Tonoplast transporters: organization and function. Annu Rev Plant Phys Mol Biol 52:469-497

Mahajan S, Tuteja N (2005) Cold, salinity and drought stresses: an overview. Arch Biochem Biophys 444(2):139-158

Mariko I, Stefan H, Sven S (2009) Salt stress affects polyamine concentrations and plasma membrane $\mathrm{H}^{+}$-ATPase proton pumping in maize. XVI International Plant Nutrition Colloquium, UC, Davis

Meratanl AA, Ghaffari SM, Niknam V (2008) Effects of salinity on growth, proteins and antioxidant enzymes in three Acanthophyllum species of different ploidy levels. JSUT 33(4):1-8

Michelet B, Boutry M (1995) The Plasma membrane $\mathrm{H}^{+}$-ATPase (a highly regulated enzyme with multiple physiological functions). Plant Physiol 108(1):1-6

Miyamoto N, Steudle E, Hirasawa T, Lafitte R (2001) Hydraulic conductivity of rice roots. J Exp Bot 52(362):1835-1846

Moller IM, Jensen PE, Hansson A (2007) Oxidative modifications to cellular components in plants. Annu Rev Plant Bio 58:459-481

Mouhaya W, Allario T, Brumos J, Andrés F, Froelicher Y, Luro F, Talon M, Ollitrault P, Morillon R (2010) Sensitivity to high salinity in tetraploid citrus seedlings increases with water availability and correlates with expression of candidate genes. Funct Plant Biol 37(7):674-685

Munns R (2002) Comparative physiology of salt and water stress. Plant Cell Environ 25(2):239-250

Munns R, James RA (2003) Screening methods for salinity tolerance: a case study with tetraploid wheat. Plant and Soil 253(1):201-218

Munns R (2005) Genes and salt tolerance: bringing them together. New Phytol 167(3):645-663

Munns R, Tester M (2008) Mechanisms of salinity tolerance. Annu Rev Plant Biol 59:651-681

Murashige T, Skoog F (1962) A revised medium for rapid growth and bioassays with tobacco tissue cultures. Plant Physiol 15:473-497

Ochiai K, Matoh T (2002) Characterization of the $\mathrm{Na}+$ delivery from roots to shoots in rice under saline stress: excessive salt enhances apoplastic transport in rice plants. Soil Sci Plant Nutr 48(3):371-378

Osborn TC, Pires JC, Birchler JA, Auger DL, Chen ZJ, Lee HS, Comai L, Madlung A, Doerge RW, Colot V, Martienssen RA (2003) Understanding mechanisms of novel gene expression in polyploids. Trends Genet 19(3):141-147

Palmgren MG (1998) Proton gradients and plant growth: role of the plasma membrane $\mathrm{H}^{+}$-ATPase. Adv Bot Res 28:1-70

Radic S, Radic'-Stojkovic M, Pevalek-Kozlina B (2006) Influence of NaCl and mannitol on peroxidase activity and lipid peroxidation in Centaurea ragusina L. roots and shoots. Plant Physiol 163(12):1284-1292

Ranathunge K, Steudle E, Lafitte R (2003) Control of water uptake by rice (Oryza sativa L.): role of the outer part of the root. Planta 217(2):193-205

Ranathunge K, Steudle E, Lafitte R (2005) Blockage of apoplastic bypass-flow of water in rice roots by insoluble salt precipitates analogous to a Pfeffer cell. Plant Cell Environ 28:121-133

Ranney TG, Bassuk NL, Whitlow TH (1991) Osmotic adjustment and solute constituents in leaves and roots of water-stressed cherry (Prunus) Trees. J Amer Soc Hort Sci 116:684-688

Ren ZH, Gao JP, Li LG, Cai XL, Huang W, Chao DY, Zhu MZ, Wang ZY, Luan S, Lin HX (2005) A rice quantitative trait locus for salt tolerance encodes a sodium transporter. Nature Genet 37:1141-1146

Rauf SD, Adil MS, Naveed A, Munir HA (2010) Response of wheat species to the contrasting saline regimes. Pak J Bot 42(5):3039-3045

Sahi C, Singh A, Kumar K, Blumwald E, Grover A (2006) Salt stress response in rice: genetics, molecular biology, and comparative genomics. Funct Integ Genom 6(4):263-284
Saleh B, Allario T, Dambier D, Ollitrault P, Morillon R (2008) Tetraploid citrus rootstocks are more tolerant to salt stress than diploid. Comp Rend Biol 331(9):703-710

Schreiber L, Hartmann K, Skrabs M, Zeier J (1999) Apoplastic barriers in roots: chemical composition of endodermal and hypodermal cell walls. J Exp Bot 50(337):1267-1280

Schreiber L, Franke R, Hartmann KD, Ranathunge K, Steudle E (2005) The chemical composition of suberin in apoplastic barriers affects radial hydraulic conductivity differently in the roots of rice (Oryza sativa L. Cv. IR64) and corn (Zea mays L. Cv. Helix). J Exp Bot 56(415):1427-1436

Shinozaki N, Yamada M, Yoshiba Y (2005) Analysis of salt-stress inducible ESTs isolated by PCR-subtraction in salt-tolerant rice. Theor Appl Genet 110(7):1177-1186

Smet ID, White PJ, Bengough AG, Dupuy L, Parizot B, Casimiro I, Heidstra R, Laskowski M, Lepetit M, Hochholdinger F, Draye X, Zhang HM, Broadley MR, Peret B, Hammond JP, Fukaki H, Mooney S, Lynch JP, Nacry P, Schurr U, Laplaze L, Benfey P, Beeckman T, Bennett M (2012) Analyzing lateral root development: how to move forward. Plant Cell 24:15-20

Soltis DE, Albert VA, Leebens M, Bell JCD, Paterson AH, Zheng C, Sankoff D (2009) Polyploidy and angiosperm diversification. Amer J Bot 96:336-348

Steudle E, Heydt H (1997) Water transport across tree roots. In: Rennenberg $\mathrm{H}_{\text {, }}$ Eschrich W, Zeiger H (eds) Trees-contribution to modern tree physiology. Backhuys Publishers, Leiden, pp 239-255

Steudle E, Peterson CA (1998) How does water get through roots? J Exp Bot 49(322):775-788

Steudle E (2000) Water uptake by roots: effects of water deficit. J Exp Bot 51(350):1531-1542

Szabados L, Savouré A (2010) Proline: a multifunctional amino acid. Trends Plant Sci 15(2):89-97

Tester M, Davenport R (2003) $\mathrm{Na}^{+}$tolerance and $\mathrm{Na}^{+}$transport in higher plants. Ann Bot 91(5):503-527

Xu WF, Shi WM (2007) Mechanisms of salt tolerance in transgenic Arabidopsis thaliana constitutively overexpressing the tomato 14-3-3 protein TFT7. Plant Soil 301:17-28

Xu WF, Jia L, Shi WM, Zhou F, Li Q, Liang J, Zhang J (2013) Abscisic acid accumulation modulates auxin transport in the root tip to enhance proton secretion for maintaining root growth under moderate water stress. New Phytol 197:139-150

Yadav R, Flowers TJ, Yeo AR (1996) The involvement of the transpirational bypass flow in sodium uptake by high and low sodium transporting lines of rice developed through intravarietal selection. Plant Cell Environ 19:329-336

Yamada M, Morishita H, Urano K, Shiozaki N, Yamaguchi-Shinozaki K, Shinozaki K, Yoshiba $Y$ (2005) Effects of free proline accumulation in petunias under drought stress. J Exp Bot 56(417):1975-1981

Yeo AR, Flowers TJ (1986) The physiology of salinity resistance in rice (Oryza sativa L.) and a pyramiding approach to breeding varieties for saline soils. Aust J Plant Physiol 13:75-91

Yeo AR, Yeo ME, Flowers TJ (1987) The contribution of an apoplastic pathway to sodium uptake by rice roots in saline conditions. J Exp Bot 38(7):1141-1153

Yildiz M, Terzi $\mathrm{H}$ (2008) Effects of $\mathrm{NaCl}$ on protein profiles of tetraploid and hexaploid wheat species and their diploid wild progenitors. Plant Soil Environ 54:227-233

Zhou QY, Li W, Cai X, Wang D, Hua XJ, Qu LQ, Lin JX, Chen T (2011) Net sodium fluxes change significantly at anatomically distinct root zones of rice (Oryza sativa L.) seedlings. Plant Physiol 168(11):1249-1255

Zhu JK (2002) Salt and drought stress signal transduction in plants. Annu Rev Plant Biol 53:247-273

Zimmermann HM, Hartmann K, Schreiber L, Steudle E (2000) Chemical composition of apoplastic transport barriers in relation to radial hydraulic conductivity of corn roots (Zea mays L.). Planta 210:302-311

Zörb C, Stracke B, Tramnitz B, Denter D, Sümer A, Mühling KH, Yan F, Schubert S (2005) Does $\mathrm{H}+$ pumping by plasmalemma ATPase limit leaf growth of maize (Zea mays) during the first phase of salt stress? J Plant Nutr Soil Sci 168:550-557

doi:10.1186/s12284-014-0015-4

Cite this article as: Tu et al:: Genome duplication improves rice root resistance to salt stress. Rice 2014 7:15. 